\title{
Haemophagocytic lymphohistiocytosis occurred during induction chemotherapy in an acute monocytic leukemia patient with FLT3-ITD and DNMT3A mutations
}

Fei $\mathrm{Li}^{1,5^{*}}$ (D) Xiaojie Zhang ${ }^{1,2+}$, Yunyun Wang ${ }^{1+}$, Ailin Yang ${ }^{1,2+}$, Zhanglin Zhang ${ }^{1}$, Weiping Tang ${ }^{1,2}$, Nan Zhong ${ }^{1,2}$ and Huidong Shi Si, $^{3}$

\begin{abstract}
Background: Haemophagocytic lymphohistiocytosis $(H L H)$ is considered to be a large challenge for clinicians due to the variable overlaps of symptoms with other severe diseases and a high rate of mortality. Prompt diagnosis and treatment are crucial to avoid a fatal outcome. However, very limited reports have focused on HLH during chemotherapy (Ch-HLH) due to a low incidence and insufficient knowledge.

Case presentation: A 22-year-old male was diagnosed with acute monocytic leukemia with FLT3-ITD and DNMT3A mutations and pulmonary infection. He received IA regimen (Idarubicin, $8 \mathrm{mg} / \mathrm{m} 2 / \mathrm{d}$ for 3 days and cytarabine, $100 \mathrm{mg} / \mathrm{m} 2 / \mathrm{d}$ for 7 days) chemotherapy, anti-infection drugs and blood components transfusions. During the stage of bone marrow suppression, he presented with a fever, cytopenia (WBC, $0.43 \times 10^{9} / \mathrm{L} ; \mathrm{Hb}, 73 \mathrm{~g} / \mathrm{L}$ and PLT, $1 \times 10^{9} / \mathrm{L}$ ), refractory coagulation dysfunction (APTT, $104.0 \mathrm{~s}$; PT, $30.5 \mathrm{~s}$ and Fbg, $0.87 \mathrm{~g} / \mathrm{L}$ ), splenomegaly ( $3 \mathrm{~cm}$ below the costal margin), hyperferritinemia (SF $>3000 \mu \mathrm{g} / \mathrm{L}$ ), increased soluble interleukin-II receptors (slL-2R $>7500 \mathrm{u} / \mathrm{mL}$ ) and haemophagocytosis in the bone marrow and was diagnosed with $\mathrm{HLH}$. After he was treated with methylprednisolone at $500 \mathrm{mg} / \mathrm{d}$ for 3 days, $120 \mathrm{mg} / \mathrm{d}$ for 3 days and $80 \mathrm{mg} / \mathrm{d}$ for 3 days, followed by a gradually reduced dose combined with powerful anti-infection drugs, his symptoms subsided and his abnormal parameters recovered to normal levels.

Conclusion: Patients with HLH in acute leukemia have a high rate of mortality. This case report provides helpful clinical experiences relative to the recognition and treatment of $\mathrm{Ch}-\mathrm{HLH}$ for clinicians.
\end{abstract}

Keywords: Haemophagocytic lymphohistiocytosis, Malignancy, Acute monocytic leukemia, FLT3-ITD, DNMT3A

\section{Background}

Secondary haemophagocytic lymphohistiocytosis (HLH) is characterized by prolonged fever, hepatosplenomegaly, cytopenia, hypertriglyceridemia, hyperferritinemia and haemophagocytosis in the bone marrow, liver, spleen or lymph nodes. It is caused

\footnotetext{
* Correspondence: yx021021@sina.com

'Xiaojie Zhang, Yunyun Wang and Ailin Yang contributed equally to this work.

${ }^{1}$ Department of Hematology, The First Affiliated Hospital of Nanchang University, 17 Yongwai Zheng Street, Nanchang 330006, Jiangxi, China ${ }^{5}$ Jiangxi Key Laboratory of Molecular Diagnosis and Precision Medicine, 17 Yongwai Zheng Street, Nanchang 330006, Jiangxi, China

Full list of author information is available at the end of the article
}

by a wide range of factors, including infections, malignancies, autoimmune diseases, metabolic diseases and acquired immune deficiencies. Of these, malignancy-associated HLH (M-HLH) is considered to be a large challenge to clinicians due to variable overlaps of symptoms with other types of HLH, sepsis and multiorgan failure, resulting in a higher incidence of misdiagnosis and mortality [1]. M-HLH can occur in newly diagnosed or relapsed malignancy (called "malignancy-triggered HLH") and during chemotherapy, especially in the treatment course of leukemia or lymphoma (called "HLH during chemotherapy", Ch-HLH). Prompt diagnosis and

(c) The Author(s). 2018 Open Access This article is distributed under the terms of the Creative Commons Attribution 4.0 International License (http://creativecommons.org/licenses/by/4.0/), which permits unrestricted use, distribution, and reproduction in any medium, provided you give appropriate credit to the original author(s) and the source, provide a link to the Creative Commons license, and indicate if changes were made. The Creative Commons Public Domain Dedication waiver (http://creativecommons.org/publicdomain/zero/1.0/) applies to the data made available in this article, unless otherwise stated. 
treatment are crucial to avoid a fatal outcome caused by multiorgan dysfunction. However, very few reports have focused on M-HLH, especially Ch-HLH, due to a low incidence and insufficient knowledge. Therefore, in this article, we present a rare case of HLH that occurred at the stage of induction chemotherapy in a patient with acute monocytic leukemia with FLT3-ITD and DNMT3A mutations.

\section{Case presentation}

A 22-year-old male was admitted to our centre due to a fever that lasted for 5 days $\left(37.5-38.5{ }^{\circ} \mathrm{C}\right)$, coughing, expectoration, nose bleed and sporadic petechiae in both lower limbs. The physical examination indicated moist rales in his lung and sporadic petechiae in both lower limbs, but no enlarged superficial lymph nodes, liver or spleen. The blood cell count revealed $25.31 \times 10^{9} / \mathrm{L}$ white blood cells (WBC) (normal range, 4-10 $\times 10^{9} / \mathrm{L}$ ) with $30 \%$ blasts, $142 \mathrm{~g} / \mathrm{L}$ haemoglobin $(\mathrm{Hb})$ (normal range, 120$150 \mathrm{~g} / \mathrm{L}$ ), $11 \times 10^{9} / \mathrm{L}$ platelets (PLT) (normal range, $100-300 \times 10^{9} / \mathrm{L}$ ), $30.6 \mathrm{~g} / \mathrm{L}$ albumin (ALB) (normal range, $40-55 \mathrm{~g} / \mathrm{L}), 303 \mathrm{U} / \mathrm{L}$ lactate dehydrogenase (LDH) (normal range, 0-248 U/L), 14 s prothrombin time (PT) (normal range, 9.8-12.1 s), $57.7 \mathrm{~s}$ activated partial prothrombin time (APTT) (normal range, 21.1-36.5 s), $18.0 \mathrm{~s}$ thrombin time (TT) (normal range, 14.0-21.0 s), $3.11 \mathrm{~g} / \mathrm{L}$ fibrinogen (Fbg) (normal range, 1.8-3.5 g/L), $688 \mu \mathrm{g} / \mathrm{L}$ serum ferritin (SF) (normal range, $30-400 \mu \mathrm{g} / \mathrm{L}$ ), $2.75 \mathrm{ng} / \mathrm{mL}$ procalcitonin (PCT) $\quad(<0.5 \mathrm{ng} / \mathrm{mL})$ and $44.5 \mathrm{mg} / \mathrm{L}$ C-reactive protein (CRP) (normal range, $0-8 \mathrm{mg} / \mathrm{L}$ ). In addition, Epstein-Barr virus (EBV) and cytomegalovirus (CMV) DNA serological tests, blood culture (veins in both upper limbs, cultures for aerobic, anaerobic and fungal agents, three times), T-spot test, (1-3)-Beta-D-Glucan assay (G test) and galactomannan assay (GM test) were all negative. The counts for alanine aminotransferase (ALT), aspartate aminotransferase (AST), bilirubin (BIL), serum creatinine (Scr) and triglycerides (TG) were normal. The computed tomography $(\mathrm{CT})$ scan examination revealed multiple high-density bilateral pulmonary parenchyma plaques, bilateral pleural effusion and a slightly enlarged spleen. The ECG showed sinus tachycardia. Echocardiography showed that the left ventricular ejection fraction was $65 \%$. A bone marrow smear revealed acute monocytic leukemia with $43 \%$ blasts (Fig. 1b). Flow cytometry revealed tumour cells that positively expressed CD38, CD13, CD64, CD11b, CD15, CD14 and HLA-DR (Fig. 1a). The chromosome karyotype was normal. FLT3-ITD Exon 11 and DNMT3A Exon 23 c.G2645A mutations were detected (Fig. 1c and d), but no
RUNX1-RUNX1T1, C-KIT/D816V, NPM1 or CEBPA mutations. Therefore, he was clinically diagnosed with acute monocytic leukemia with FLT3-ITD and DNMT3A mutations and pulmonary infection. He received IA regimen chemotherapy (Idarubicin, $8 \mathrm{mg} / \mathrm{m}^{2} / \mathrm{d}$, for 3 days and cytarabine, $100 \mathrm{mg} / \mathrm{m}^{2} / \mathrm{d}$, for 7 days), anti-infection drug treatments (Imipenem/cilastatin, vancomycin hydrochloride and voriconazole, time from admission to d6 during the stage of IA chemotherapy) and blood components transfusions.

In the following days, his lung infection gradually improved and his body temperature decreased to the normal level. SF, PCT and CRP decreased to $324 \mu \mathrm{g} / \mathrm{L}, 0.75 \mathrm{ng} / \mathrm{mL}$ and $25.4 \mathrm{mg} / \mathrm{L}$, respectively. Multiple high-density bilateral pulmonary parenchyma plaques were obviously absorbed. However, due to bone marrow suppression after chemotherapy, he developed a fever again, his body temperature was increased to over $39{ }^{\circ} \mathrm{C}$ and his blood cell counts decreased to $0.43 \times 10^{9} / \mathrm{L}$ WBC, $73 \mathrm{~g} / \mathrm{L} \mathrm{Hb}$ and $1 \times 10^{9} / \mathrm{L}$ PLT in the 11 days after finishing IA chemotherapy. To our surprise, his coagulation dysfunction worsened, with APTT and PT prolonged to $104.0 \mathrm{~s}$ and $30.5 \mathrm{~s}$, respectively, and Fbg decreased to $0.87 \mathrm{~g} / \mathrm{L}$. TT and the plasma protamine paracoagulation test (3P test) were normal. PCT and CRP increased to $3.8 \mathrm{ng} / \mathrm{mL}$ and $35.7 \mathrm{mg} / \mathrm{L}$ again, respectively. Serological tests for EBV-DNA and CMV-DNA, a blood culture, the G test and the GM test were still negative. The levels of ALT, AST, BIL, Scr and TG were normal. The patient was originally diagnosed with severe infection, systemic inflammatory response syndrome (SIRS), and disseminated intravascular coagulation (DIC) and was treated with $80 \mathrm{mg} / \mathrm{d}$ methylprednisolone for 3 days (from d11 to d13 after finishing chemotherapy), fresh frozen plasma, platelets, cryoprecipitate anti-fibrinolysis drugs, and powerful antibiotics, including cefoperazone/sulbactam, tigecycline and voriconazole (from d10 after finishing chemotherapy until his temperature returned to the normal level and granulocytic deficiency resolved). However, his coagulation dysfunction did not improve and his peripheral blood cells were not restored at 14 days after finishing IA chemotherapy following the above treatments. He was subjected to bone marrow aspiration. Surprisingly, cell proliferation in his bone marrow was extremely active, with $7 \%$ blasts and 5\% haemophagocytic cells (Fig. 2a and b). In addition, his SF was $>3000 \mu \mathrm{g} / \mathrm{L}$, soluble interleukin-II receptor (sIL-2R) was $>7500 \mathrm{u} / \mathrm{mL}$, and spleen was $3 \mathrm{~cm}$ below the left costal margin. Table 1 shows the patient's clinical parameters. Based on the fever, hypofibrinogenemia, 


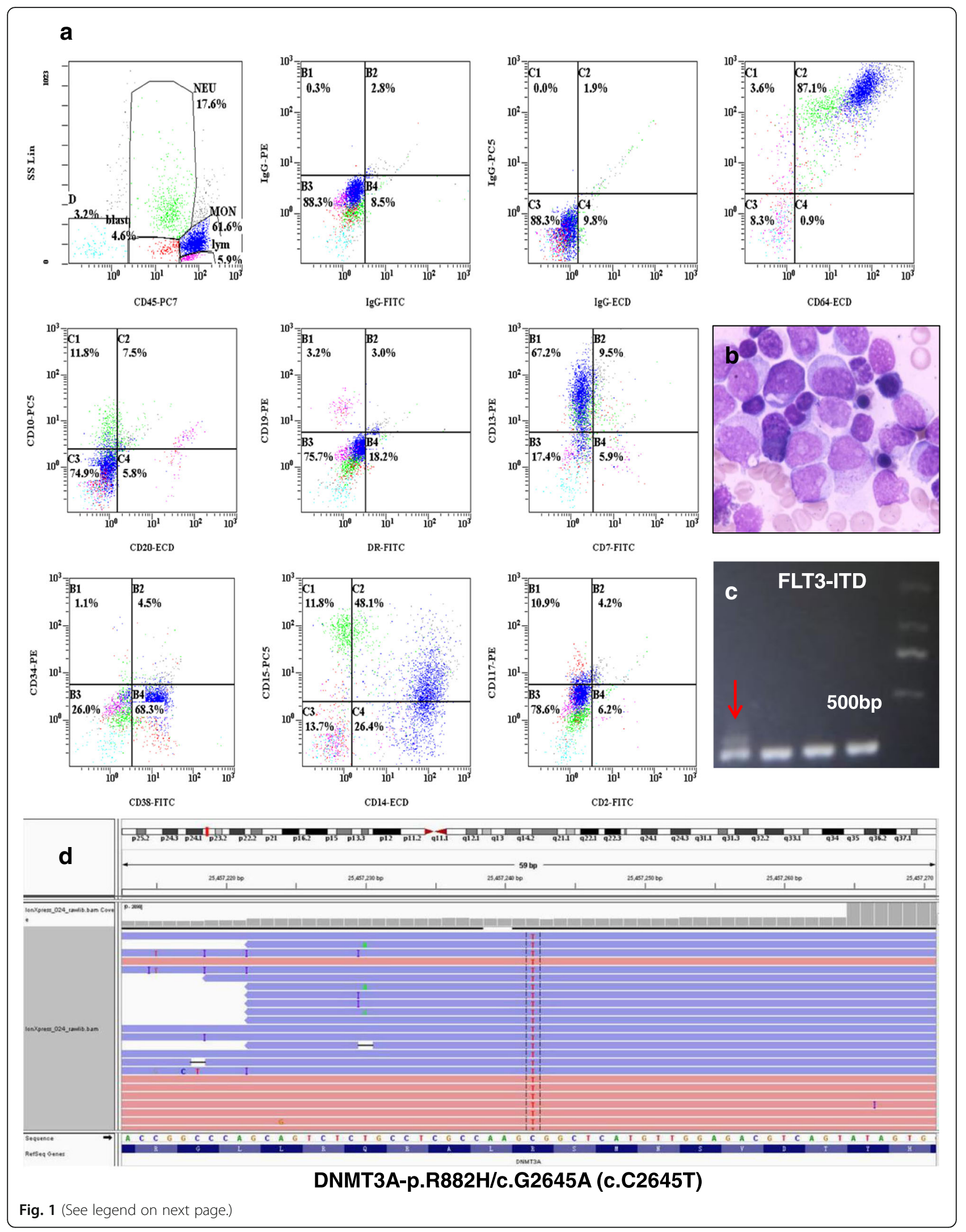


(See figure on previous page.)

Fig. 1 The patient was diagnosed with AML with FLT3-ITD and DNMT3A mutations. a Flow cytometry indicated that the leukemia cells positively expressed CD38, CD13, CD64, CD11b, CD15, CD14 and HLA-DR. b The bone marrow smear revealed AML. c FLT3-ITD Exon 11 mutation was found using PCR amplicon analyses. d DNMT3A Exon 23 c.G2645A mutations were found by next generation sequencing analyses using IGV software

splenomegaly, cytopenia, hyperferritinemia, increased sIL-2R and haemophagocytosis in bone marrow, he was diagnosed with HLH. Because of incomplete cytokine storms blockade, the previous dose of methylprednisolone presumably did not effectively suppress HLH. Therefore, he was given $500 \mathrm{mg} / \mathrm{d}$ of methylprednisolone for 3 days (d14-16 after finishing chemotherapy), $120 \mathrm{mg} / \mathrm{d}$ for d17-19, and $80 \mathrm{mg} / \mathrm{d}$ for $\mathrm{d} 20-22$, followed by a gradually reduced dose. Eventually, his temperature dropped to the normal level, his coagulation dysfunction gradually improved, with an APTT of $46.2 \mathrm{~s}$, PT of $11.8 \mathrm{~s}$ and Fbg of $4.82 \mathrm{~g} / \mathrm{L}$, and his peripheral blood cells were restored to $15.0 \times 10^{9} / \mathrm{L} \mathrm{WBC}, 78 \mathrm{~g} / \mathrm{L} \mathrm{Hb}$ and $42 \times 10^{9} / \mathrm{L}$ PLT. However, $34 \%$ of blasts were still observed in the bone marrow smear at 20 days after finishing IA chemotherapy. The patient is still alive and being followed. Figure 3 shows the treatment course of the patient.

\section{Discussion}

In recent years, M-HLH with a high rate of misdiagnosis and mortality has gained increasing attention from clinicians because its symptoms are nonspecific and overlap with some severe illnesses, including sepsis, SIRS and multiorgan failure. The most common tumour types that trigger $\mathrm{HLH}$ are haematological neoplasms (93.7\%) with T-cell or natural-killer (NK) lymphoma or leukemia (35.2\%), followed by B-cell lymphoma $(31.8 \%)$, other non-specified hematologic neoplasms (14.4\%) and Hodgkin lymphoma (5.8\%). Of these, leukemia-triggered HLH accounted for only $6.4 \%$ of cases [2-4]. According to consensus recommendations for the diagnosis and management of HLH-associated malignancies, M-HLH can occur in the phase of diagnosis or chemotherapy, including induction, consolidation, and even maintenance $[2,5]$.

So far, very few sporadic reports on M-HLH during the onset of acute myeloid leukemia (AML) or course of chemotherapy have been reported [6-10]. Excessive cytokines secreted by malignant cells and/ or viruses may be the cause of AML-triggered HLH, and viruses, invasive fungi and bacterial infections after chemotherapy may be the major triggers of Ch-HLH. In the present case, the patient had a fever, hypofibrinogenemia, splenomegaly, cytopenia, hyperferritinemia, increased sIL-2R levels and haemophagocytosis in the bone marrow during the induction of chemotherapy, fulfilling the diagnostic criteria of HLH 2004 [11]. Lehmberg et al. [10] reported 21 cases of M-HLH. Among these, 8 patients had Ch-HLH, including 2 cases of AML, 5 cases of acute lymphoblastic leukemia (ALL) and 1 case of lymphoma; 6 patients occurred in the stage of remission; and 2 patients occurred in the stage of induction chemotherapy. In addition, E. coli, EBV, HHV6, aspergillus, adenovirus and CMV were found in the seven patients. Although we actively sought infectious causes, including EBV, CMV, and herpes simplex virus, and performed a blood culture, a G test and a GM test, the positive triggers remained unclear. It is possible that HLH was co-triggered by excessive cytokine secretion by leukemia cells and lung infection in this patient.

Patients with M-HLH and Ch-HLH show very poor survival, with a median overall survival of $0.9-$

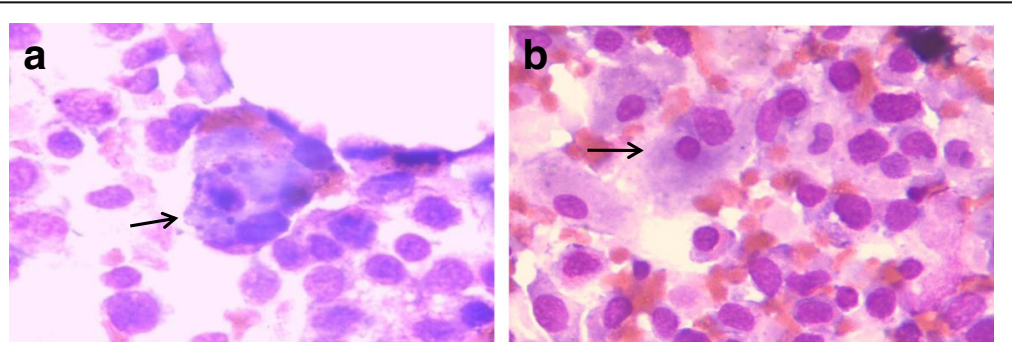

Fig. 2 The bone marrow cell morphology of the patient at 14 days after finishing IA chemotherapy. $\mathbf{a}$ and $\mathbf{b}$ indicate haemophagocytic cells (at the arrowhead) and some promonocytes can be seen in the bone marrow smear (Wright-Giemsa staining, $\times 1,000$ ) 
Table 1 The clinical parameters of the patient

\begin{tabular}{lllll}
\hline Parameters & Before chemotherapy & d6 during the IA chemotherapy & d11-14 after finishing chemotherapy & d20 after finishing chemotherapy \\
\hline WBC $\left(\times 10^{9} / \mathrm{L}\right)$ & 25.3 & 3.2 & 0.4 & 15.0 \\
$\mathrm{Hb}(\mathrm{g} / \mathrm{L})$ & 142 & 66 & 73 & 78 \\
$\mathrm{PLT}\left(\times 10^{9} / \mathrm{L}\right)$ & 11.0 & 5 & 1 & 42 \\
$\mathrm{APTT}(\mathrm{s})$ & 57.7 & 72 & 104 & 46.2 \\
$\mathrm{PT}(\mathrm{s})$ & 14.0 & 14.6 & 30.5 & 11.8 \\
$\mathrm{Fbg}(\mathrm{g} / \mathrm{L})$ & 3.1 & 2.2 & 0.87 & 4.8 \\
$\mathrm{TG}(\mathrm{mmol} / \mathrm{L})$ & 1.5 & - & 0.8 & 0.9 \\
$\mathrm{SF}(\mu \mathrm{g} / \mathrm{L})$ & 688 & 324 & $>3000$ & 1259 \\
$\mathrm{PCT}(\mathrm{ng} / \mathrm{mL})$ & 2.8 & 0.75 & 3.8 & 0.7 \\
$\mathrm{CRP}(\mathrm{mg} / \mathrm{L})$ & 44.5 & 25.4 & 35.7 & 49.1 \\
$\mathrm{LDH}(\mathrm{U} / \mathrm{L})$ & 303 & 481 & 57 & 392
\end{tabular}

WBC white blood cell (normal range, 4-10 $\times 10^{9} / \mathrm{L}$ ), $\mathrm{Hb}$ hemoglobin (normal range, $120-150 \mathrm{~g} / \mathrm{L}$ ), PLT platelet (normal range,100-300 $\times 10^{9} / \mathrm{L}$ ), APTT activated partial prothrombin time (normal range, 21.1-36.5 s), $P$ T prothrombin time (normal range, 9.8-12.1 s), Fbg fibrinogen (normal range, 1.8-3.5 g/L), TG triglycerides (normal range, 0-1.7 mmol/L), SF serum ferritin (normal range, 30-400 $\mu \mathrm{g} / \mathrm{L}$ ), $P C T$ :procalcitonin $(<0.5 \mathrm{ng} / \mathrm{mL}$ ), CRP C-reactive protein (normal range, $0-8 \mathrm{mg} / \mathrm{L}$ ), $L D H$ lactate dehydrogenase (normal range, $0-248 \mathrm{U} / \mathrm{L}$ ), IA regimen idarubicin, $8 \mathrm{mg} / \mathrm{m}^{2} / \mathrm{d}$ at d1-3, Cytarabine, $100 \mathrm{mg} / \mathrm{m}^{2} / \mathrm{d}$ at d1-7

1.2 years and 6-month survival rates of 67 and $63 \%$, respectively $[2,10]$. This patient had FLT3-ITD Exon 11 and DNMT3A Exon 23 c.G2645A mutations, which predict a worse prognosis. In fact, the patient was refractory to chemotherapy and achieved no remission after a cycle of standard regimen chemotherapy. The relationship between HLH and some subtypes of leukemia such as FLT3-ITD and/or DNMT3A mutations is unclear.

The best therapeutic approach for Ch-HLH remains elusive. Based on iatrogenic immunosuppression and consecutive triggering infections, if infections are detected in patients with Ch-HLH, the consensus is that chemotherapy should be postponed and powerful anti-infection treatment should be considered first [2]. In the present case, the patient was given $80 \mathrm{mg} / \mathrm{d}$ methylprednisolone for 3 days and fresh frozen plasma, platelets, cryoprecipitate, anti-fibrinolysis drugs and powerful antibiotics to control the inflammation response and his coagulation dysfunction. However, his abnormal parameters did not improve or become restored. Due to an uncontrolled hyperinflammation response, he was then treated with methylprednisolone at $500 \mathrm{mg} / \mathrm{d}$ for 3 days and $120 \mathrm{mg} / \mathrm{d}$ for 3 days, followed by a gradually reduced dose. His temperature and coagulation dysfunction were then successfully controlled to normal levels, suggesting that a sufficient dose of glucocorticosteroids may be effective to control the hyperinflammation response in Ch-HLH patients.

\section{Conclusions}

In summary, Ch-HLH is a life-threatening disease with very high mortality. Early recognition, a sufficient dose of glucocorticosteroids and regulation of the hyperinflammation response are crucial to avoid a fatal outcome due to multiorgan dysfunction and improve the overall survival of these patients. The present case report may provide some clinical experiences regarding the recognition and treatment of Ch-HLH for clinicians.

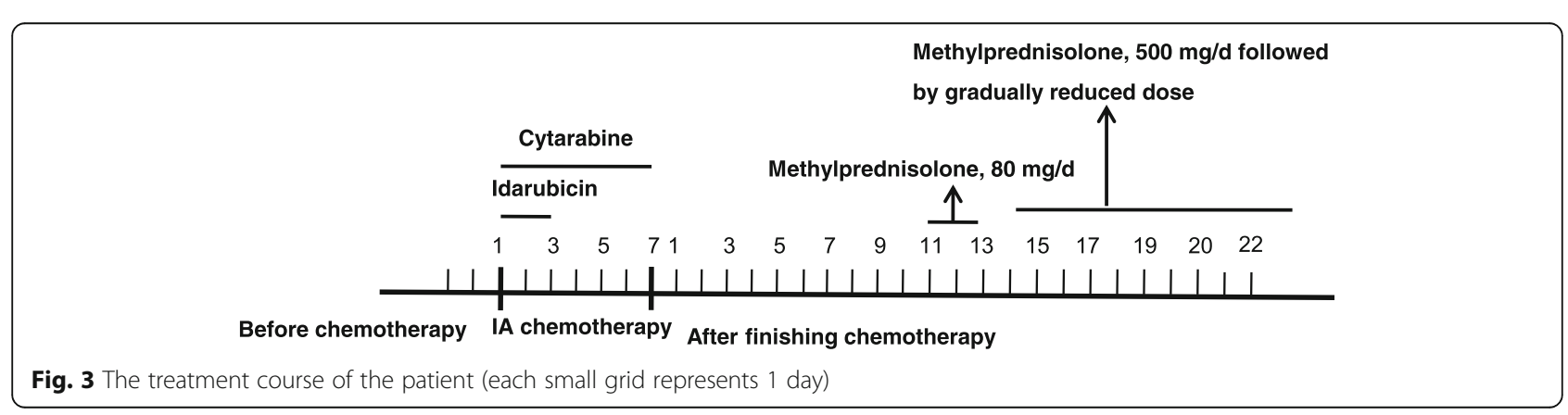




\section{Abbreviations}

3P test: plasma protamine paracoagulation test; ALB: Albumin; ALL: Acute lymphoblastic leukemia; ALT: Alanine aminotransferase; AML: Acute myeloid leukemia; APTT: Activated partial prothrombin time; AST: Aspartate aminotransferase; BIL: Bilirubin; CMV: Cytomegalovirus; CRP: C-reactive protein; CT: Computed tomography; DIC: Disseminated intravascular coagulation; EBV: Epstein-Barr virus; Fbg: Fibrinogen; G test: (1-3)-Beta-DGlucan Assay; GM test: Galactomannan assay; Hb: Haemoglobin; HLH: Secondary haemophagocytic lymphohistiocytosis; IA regimen: Idarubicin and cytarabine; LDH: Lactate dehydrogenase; MHLH: Malignancy-associated HLH; PCT: Procalcitonin; PLT: Platelets; PT: Prothrombin time; Scr: Serum creatinine; SF: Serum ferritin; sIL-2R: Soluble interleukin-II receptor; SIRS: Systemic inflammatory response syndrome; TG: Triglycerides; TT: Thrombin time; WBC: White blood cell

\section{Funding}

This work is financially supported by grants from the National Natural Science Foundation of China (81360353, 81560034, 81560036), the Natural Science Foundation of Jiangxi province (20142BAB205072) and the Young Scientist Training Program (20153BCB23040) of Jiangxi Province.

\section{Availability of data and materials}

The raw data supporting our findings can be requested from the corresponding author.

\section{Authors' contributions}

$X Z, Y W$ and $A Y$ designed and wrote the manuscript. ZZ, WT, NZ and HS contributed to the review and revision of the manuscript. FL contributed to the final review and approval of the manuscript. All authors read and approved the final version of the manuscript.

\section{Ethics approval and consent to participate}

The study was reviewed and approved by the First Affiliated Hospital of Nanchang University.

\section{Consent for publication}

Written informed consent was obtained from the patient for the publication of this case report and the accompanying images.

\section{Competing interests}

The authors declare that they have no competing interests.

\section{Publisher's Note}

Springer Nature remains neutral with regard to jurisdictional claims in published maps and institutional affiliations.

\section{Author details}

'Department of Hematology, The First Affiliated Hospital of Nanchang University, 17 Yongwai Zheng Street, Nanchang 330006, Jiangxi, China. ${ }^{2}$ Medical College, Nanchang University, Nanchang 330006, China. ${ }^{3}$ Georgia Cancer Center, Augusta University, Augusta, GA 30912, USA. ${ }^{4}$ Department of Biochemistry and Molecular Biology, Medical College of Georgia, Augusta University, Augusta, GA 30912, USA. ${ }^{5}$ Jiangxi Key Laboratory of Molecular Diagnosis and Precision Medicine, 17 Yongwai Zheng Street, Nanchang 330006, Jiangxi, China.

Received: 14 February 2017 Accepted: 21 May 2018

Published online: 29 May 2018

\section{References}

1. Li F, Yang Y, Jin F, Dehoedt C, Rao J, Zhou Y, et al. Clinical characteristics and prognostic factors of adult hemophagocytic syndrome patients: a retrospective study of increasing awareness of a disease from a singlecenter in China. Orphanet J Rare Dis. 2015;10:20.

2. Lehmberg K, Nichols KE, Henter II, Girschikofsky M, Greenwood T, Jordan M et al. Consensus recommendations for the diagnosis and management of hemophagocytic lymphohistiocytosis associated with malignancies. Haematologica. 2015;100(8):997-1004

3. Ramos-Casals M, Brito-Zerón P, López-Guillermo A, Khamashta MA, Bosch X Adult haemophagocytic syndrome. Lancet. 2014;383(9927):1503-16.
4. Machaczka M, Klimkowska M, Chiang SC, Meeths M, Muller ML, Gustafsson $B$, et al. Development of classical Hodgkin's lymphoma in an adult with biallelic STXBP2 mutations. Haematologica. 2013;98(5):760-4.

5. Machaczka M, Vaktnas J, Klimkowska M, Hagglund H. Malignancy-associated hemophagocytic lymphohistiocytosis in adults: a retrospective populationbased analysis from a single center. Leuk Lymphoma. 2011;52(4):613-9.

6. Yamazaki S, Nakamura F, Nasu R, Nannya Y, Ichikawa M, Kurokawa M. Haemophagocytic lymphohistiocytosis is are recurrent and specific complication of acute erythroid leukaemia. Br J Haematol. 2011;153(5):669-72.

7. Zhao D, Qian L, Shen J. Acute myelocytic leukemia in a patient with hemophagocytic lymphohistiocytosis: a case report. Oncol Lett. 2014;8(6):2634-6.

8. Lackner H, Seidel MG, Strenger V, Sovinz P, Schwinger W, Benesch M. Haemophagocytic syndrome in children with acute monoblastic leukemiaanother cause of fever of unknown origin. Support Care Cancer. 2013 21(12):3519-23.

9. Delavigne K, Bérard E, Bertoli S, Corre J, Duchayne E, Demur C, et al. Haemophagocytic syndrome in patients with acute myeloid leukemia undergoing intensive chemotherapy. Haematologica. 2014;99(3):474-80.

10. Lehmberg K, Sprekels B, Nichols KE, Woessmann W, Müller I, Suttorp M, et al. Malignancy- associated haemophagocytic lymphohistiocytosis in children and adolescents. Br J Haematol. 2015;170(4):539-49.

11. Henter II, Horne A, Arico M, Egeler RM, Filipovich AH, Imashuku S, et al. HLH-2004: diagnostic and therapeutic guidelines for hemophagocytic lymphohistiocytosis. Pediatr Blood Cancer. 2007;48(2):124-31.

\section{Ready to submit your research? Choose BMC and benefit from:}

- fast, convenient online submission

- thorough peer review by experienced researchers in your field

- rapid publication on acceptance

- support for research data, including large and complex data types

- gold Open Access which fosters wider collaboration and increased citations

- maximum visibility for your research: over $100 \mathrm{M}$ website views per year

At BMC, research is always in progress.

Learn more biomedcentral.com/submissions 